\title{
A Cone Beam CT-Based Study For Clinical Target Definition Using Pelvic Anatomy During Post-Prostatectomy Radiotherapy
}

\author{
Timothy Showalter MD \\ Thomas Jefferson University, timothy.showalter@jefferson.edu
}

\author{
A. Omer Nawaz, MA \\ Department of Radiation Oncology, Thomas Jefferson University, omer.nawaz@jefferson.edu
}

Ying Xiao

Thomas Jefferson University, ying.xiao@jefferson.edu

James Galvin PhD

Thomas Jefferson University, james.galvin@jefferson.edu

Richard K. Valicenti, MD

Pepartment of Radjation Oncology Thomas Jefferson University richard.valicenti@jefferson.edu Follow this and additional works at: https://jdc.jefferson.edu/bodinejournal

Part of the Oncology Commons

Let us know how access to this document benefits you

\section{Recommended Citation}

Showalter, Timothy MD; Nawaz, MA, A. Omer; Xiao, Ying; Galvin, James PhD; and Valicenti, MD, Richard K. (2008) "A Cone Beam CT-Based Study For Clinical Target Definition Using Pelvic Anatomy During PostProstatectomy Radiotherapy," Bodine Journal: Vol. 1 : Iss. 1 , Article 3.

DOI: https://doi.org/10.29046/TBJ.001.1.002

Available at: https://jdc.jefferson.edu/bodinejournal/vol1/iss1/3

This Article is brought to you for free and open access by the Jefferson Digital Commons. The Jefferson Digital Commons is a service of Thomas Jefferson University's Center for Teaching and Learning (CTL). The Commons is a showcase for Jefferson books and journals, peer-reviewed scholarly publications, unique historical collections from the University archives, and teaching tools. The Jefferson Digital Commons allows researchers and interested readers anywhere in the world to learn about and keep up to date with Jefferson scholarship. This article has been accepted for inclusion in Bodine Journal by an authorized administrator of the Jefferson Digital Commons. For more information, please contact: JeffersonDigitalCommons@jefferson.edu. 


\section{A Cone Beam CT-Based Study For Clinical Target Definition Using Pelvic Anatomy During Post-Prostatectomy Radiotherapy}

Timothy N. Showalter, MD, A. Omer Nawaz, MA, Ying Xiao, PhD, James M. Galvin DSc, Richard K. Valicenti MD

Department of Radiation Oncology, Kimmel Cancer Center, Thomas Jefferson University, Philadelphia, Pennsylvania

The following article is reprinted with permission from Elsevier Inc. It was originally published in the Int. J. Radiation Oncol. Biol. Physics, Volume 70, Issue 2, pages 431-436, Feb. 1, 2008.

\section{Introduction}

Radiation therapy (RT) is delivered after radical prostatectomy (RP) either as salvage treatment for an elevated prostate-specific antigen (PSA) level ${ }^{1-6}$ or as adjuvant therapy for patients with highrisk pathologic features ${ }^{7-8}$. Recent prospective data demonstrated a disease-free survival benefit of adjuvant RT for pathologic T3N0 prostate cancer $^{9-10}$. Despite literature supporting the delivery of post-RP RT to the prostatic fossa (PF), no clear target definition guidelines exist for intensity modulated radiation therapy (IMRT) or image-guided RT (IGRT) ${ }^{11}$.

Visualization of the PF is limited on standard CT images, with significant interobserver variability and uncertainty in CTV definition ${ }^{12}$. Efforts to incorporate complementary imaging modalities such as MRI for PF target volume definition have generated neither demonstrably more reliable PF delineation, nor practical contouring guidelines ${ }^{13}$. Regardless of the imaging modality, direct visualization and delineation of the PF clinical target volume (CTV) is fraught with uncertainty. On the other hand, it is possible to distinguish the borders of important nearby pelvic structures, namely the bladder and the rectum. The reliability of rectal volume definition on helical CT is supported by analysis of rectal contours defined in a prospective trial, suggesting the feasibility of rectal dose-volume data collection in a multicenter setting ${ }^{14}$. Fiorino et al have described a correlation between PF CTV shift and anterior rectal wall shift for the cranial half of the rectum in their report of rectal and bladder movement during post-RP RT using weekly CT images ${ }^{15}$. These studies support the reliability of CT-defined rectum contours and a limited correlation between PF CTV and anterior rectal wall, an important tenet in the current study.

The data reported by Fiorino et al. are limited by the infrequency of image collection and the acquisition of images at a time and place separate from the treatment couch. Though PTV margin recommendations are not provided by Fiorino et al., they state eloquently that 1 ), the anteriorposterior movements of rectum and bladder are more important than lateral motion; 2), the rectum trends anteriorly during an RT course; 3 ), there is significant correlation between the posterior CTV border and the anterior rectal wall for the cranial half of the rectum ${ }^{15}$. Through the use of CBCT images obtained during post-prostatectomy RT, the interfraction movement of the dose-limiting pelvic organs may be characterized further. This information may be used for the careful extrapolation of information regarding motion of the PF target volume. Prior reports have described the utility of online СBCT imaging during definitive, primary RT for prostate cancer using equipment similar to that utilized in the current study ${ }^{16}$.

In our study, we approach the problem of PF target definition through analysis of real-time $\mathrm{CBCT}$ images during post-RP RT, studying the motion of the critical normal tissue structures that approximate the anterior and posterior anatomical boundaries of the prostatic fossa. Conebeam CT images, obtained during a definitive course of RT, provided information regarding rectal and bladder movement. For the purpose of estimating appropriate anterior and posterior PF PTV definition guidelines, the posterior bladder border and the anterior rectum border were considered as radiographic surrogates for the anterior and posterior PF borders, respectively.

\section{Methods and Materials}

The pelvic anatomy of 10 consecutive prostate cancer patients undergoing post-RP RT was studied retrospectively using CBCT images obtained during the course of treatment. All patients received a radiation dose of $68.4 \mathrm{~Gy}(1.8 \mathrm{~Gy} /$ fraction), delivered with a four-field conformal RT plan. Planning CT $\left(\mathrm{CT}_{\text {ref }}\right)$ scans, with $3 \mathrm{~mm}$ slice thickness, were obtained in the supine position with contrast dye cystograms and urethrograms. Patients were instructed to follow a strict preparatory regimen before the $\mathrm{CT}_{\text {ref }}$ and during $\mathrm{RT}$ in order to ensure consistent filling and emptying of the bladder and rectum, respectively. The attending physician (R.V.) reviewed and approved $\mathrm{CTV}$, rectum, and bladder $\mathrm{CT}_{\text {ref }}$ volumes on the helical CT scans for each patient as a component of standard RT planning and delivery. At our institution, a standard $1.0 \mathrm{~cm}$ PTV margin is added to the prostatic fossa CTV, an empirically chosen guideline. The standard post-RP treatment policy in our department includes at least every-other-day CBCT scans for position verification, with corrective shifts for $5 \mathrm{~mm}$ or more. Image registration using CBCT scans is performed based upon bony anatomy including femoral heads, pubic arch, sacrum, ischium and ilium. CBCT images were obtained 2-5 times weekly immediately before treatment using the Elekta Synergy ${ }^{\oplus}$ cone beam system.

CBCT scans (exported with a $1 \mathrm{~mm}$ slice thickness) were registered in relation to the planning CT using the mutual information algorithm on the CMS FocalSim ${ }^{\circ}$. The automatically co-registered images were evaluated for accuracy by a single observer (T.S.); manual adjustments

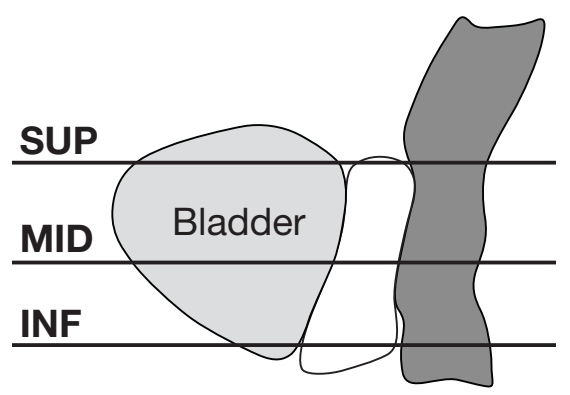

Figure 1. Rectum and bladder motion were recorded at three points along the distance from seminal vesicle stump to bladder-urethral junction. 
Table 1. Characteristics of 10 patients receiving radiotherapy to $\mathrm{PF}$ after radical prostatectomy

\begin{tabular}{ll}
\hline Age (years) & 57 \\
Mean & $44-69$ \\
Range & \\
\hline Time from surgery to RT & 8.2 \\
Median (months) & 6 \\
$\leq 9$ months (n) & 4 \\
$>9$ months (n) & \\
\hline Pre-RT PSA (n) & 6 \\
$\leq 0.4$ & 4 \\
$>0.4$ & 2 \\
\hline Gleason Score (n) & 8 \\
GS $=6$ & \\
GS $=7$ & 5 \\
\hline Pathologic Tumor Stage (n) & 5 \\
pT2 & \\
pT3 & 6 \\
\hline Extracapsular extension (n) & 4 \\
Yes & \\
No & \\
\hline Margin status & \\
Positive & \\
Negative & \\
\hline
\end{tabular}

were made when necessary to produce an optimal fusion of images in relation to the bony pelvic anatomy. The same observer contoured bladder and rectal volumes on all CBCT images of satisfactory quality for the identification of the rectal and bladder borders. Rectal and bladder motion was measured from the seminal vesicle stump (SVS) to the bladder-urethral junction (BUJ) (Figure 1). This region was chosen since it represents the volume at risk for subclinical disease and it includes the relevant, potentially dose-limiting organs-at-risk (OAR). For each patient, 3 cross-sectional levels were studied: 1 ) superior (SUP), one slice caudal to the SVS; 2) inferior (INF), one slice cranial to the BUJ; and 3) middle (MID), midway between SUP and INF levels. In the crosssectional plane, midsagittal coordinates were measured at the anterior rectal border and the posterior bladder border and compared to the planning CT volumes and the mean organ position to obtain interfraction motion. Lateral shifts were not assessable with this technique, and were not studied due to minimal impact on RT dose delivered to adjacent organs at risk (bladder and rectum) relative the anterior and posterior shifts. Inter-organ distance (IOD), the midsagittal difference between bladder and rectum, was also recorded at each measurement level, as this quantity may approximate crudely the anteroposterior PF distance. Data regarding organ volume and movement were collected for each $\mathrm{CT}_{\text {ref }}$ and CBCT. The mean and the standard deviation of organ border motion were calculated relative to both $\mathrm{CT}_{\text {ref }}$ and mean organ position.

In order to assess the reproducibility of the rectum and bladder by volume definition, repeat contours of the rectum and bladder were performed for 2 patients. In separate contouring sessions, the sameobserver (T.S.) repeated the organ definition steps using all CBCT scans for both patients. Repeat measurements of the anterior rectal border and the posterior bladder border were recorded, and movement relative to $\mathrm{CT}_{\text {ref }}$ was collected. The difference between the two sets of CBCT organ contours was calculated to determine the intraobserver variability for bladder and rectum
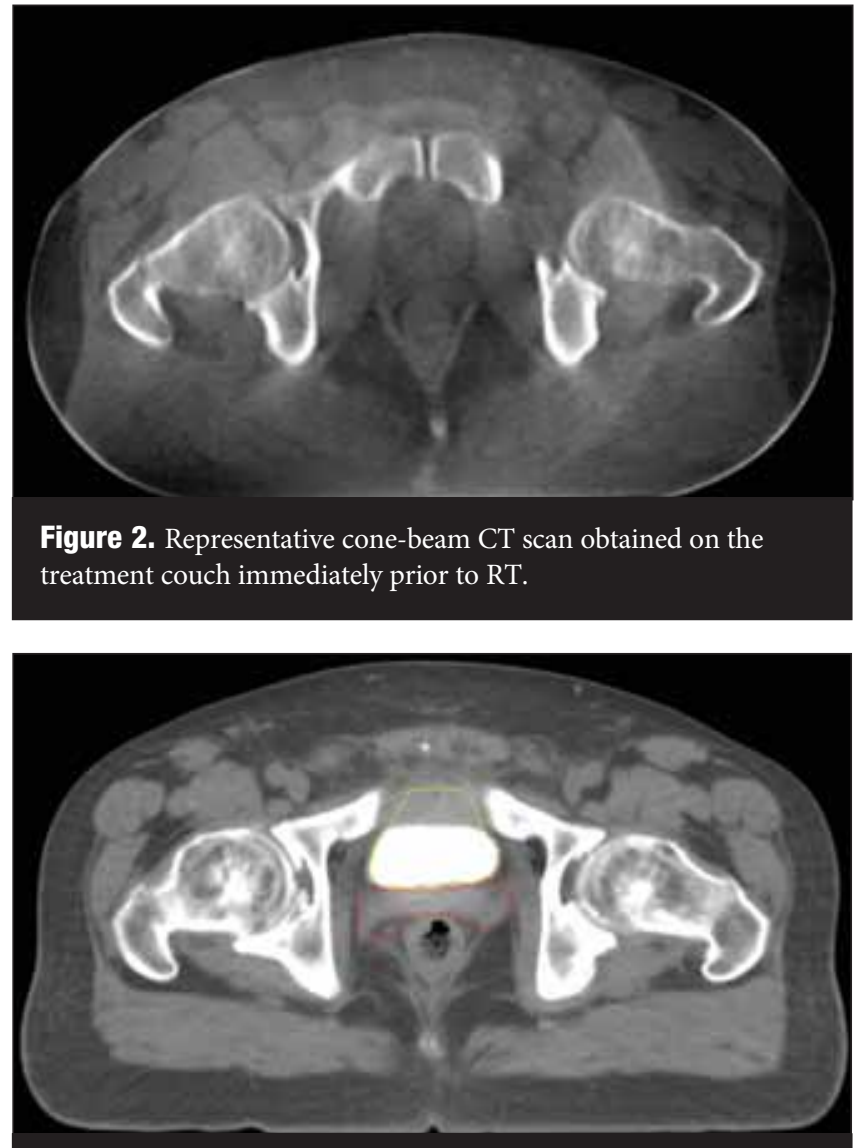

Figure 3. Sample treatment planning CT scan $\left(\mathrm{CT}_{\mathrm{ref}}\right)$ obtained prior to initiation of RT.

motion measurements. A similar process was followed for rectum and bladder volume measurements to determine intraobserver variation in organ volume.

Anterior and posterior PTV margins were calculated by applying a formula $(2 \Sigma+0.7 \sigma)$ that includes systematic error $(\Sigma)$ and random error $(\sigma)$ of target volume position ${ }^{17}$, using measured organ border shifts relative to $\mathrm{CT}_{\text {ref }}$ for each CBCT scan. Interfraction motion of the posterior bladder border and the anterior rectum border were used in the analysis as substitutes for anterior and posterior PF motion in order to calculate estimated margin recommendations.

\section{Results}

Ten patients undergoing prostatic fossa RT to $68.4 \mathrm{~Gy}$ in 38 fractions were evaluable for this study. Demographic data is displayed in Table 1. A total of 176 СBCT study sets obtained 3-5 times weekly were analyzed. The rectal and bladder borders were reliably identified in 166 of 176 (93\%) of CBCT images. Figure 2 shows a representative $\mathrm{CBCT}$ image. Figure 3 contains a typical CT image obtained for planning purposes.

\section{Validation of Methods}

Repeat contours and measurements for two patients reveal an average organ movement measurement discrepancy between contour sets of $1.2 \pm$ $1.7 \mathrm{~mm}$ for bladder and $1.1 \pm 1.0 \mathrm{~mm}$ for rectum for each of thirty CBCT 
Table 2. Organ motion and suggested margin guidelines based on systematic and random error.

\begin{tabular}{|c|c|c|c|c|c|c|}
\hline Observed Motion & \multicolumn{3}{|c|}{$\begin{array}{c}\text { Bladder Motion } \\
(\mathrm{mm})\end{array}$} & \multicolumn{3}{|c|}{$\begin{array}{c}\text { Rectal Motion } \\
(\mathrm{mm})\end{array}$} \\
\hline Relative to Mean & SUP & MID & INF & SUP & MID & INF \\
\hline $\begin{array}{c}\mathrm{CT}_{\text {ref }} \quad \mathrm{SD} \\
(+=\text { anterior } \\
-=\text { posterior })\end{array}$ & $\begin{array}{r}+0.1 \\
4.4\end{array}$ & $\begin{array}{r}+0.4 \\
3.7\end{array}$ & $\begin{array}{r}+1.5 \\
4.0\end{array}$ & $\begin{array}{r}-2.6 \\
6.0\end{array}$ & $\begin{array}{r}-1.6 \\
6.3\end{array}$ & $\begin{array}{r}-2.7 \\
5.8\end{array}$ \\
\hline $\begin{array}{l}\text { Relative to } \\
\text { mean organ } \\
\text { position for }\end{array}$ & $\begin{array}{l}3.3 \\
2.9\end{array}$ & $\begin{array}{l}2.9 \\
2.4\end{array}$ & $\begin{array}{l}3.1 \\
2.9\end{array}$ & $\begin{array}{l}4.7 \\
4.6\end{array}$ & $\begin{array}{l}4.8 \\
4.4\end{array}$ & $\begin{array}{l}4.5 \\
4.6\end{array}$ \\
\hline Systematic Error $(\Sigma)$ & 2.4 & 2.1 & 2.1 & 3.5 & 3.5 & 3.1 \\
\hline Random Error $(\Sigma)$ & 3.3 & 2.8 & 2.4 & 4.0 & 4.5 & 3.5 \\
\hline $\begin{array}{l}\text { Calculated PTV } \\
\text { Margin }(2 \Sigma+0.7 \Sigma)\end{array}$ & 7.1 & 6.2 & 5.9 & 9.8 & 10.2 & 8.6 \\
\hline
\end{tabular}

study sets analyzed. Average variation at SUP, MID, and INF levels for bladder was $1.0 \pm 1.4 \mathrm{~mm}, 1.0 \pm 1.3 \mathrm{~mm}, 1.5 \pm 2.5 \mathrm{~mm}$, and, for rectum, 1.1 $\pm 1.2 \mathrm{~mm}, 1.1 \pm 0.8 \mathrm{~mm}$, and $1.1 \pm 1.1 \mathrm{~mm}$, respectively. Mean difference in bladder volume between the CBCT contours was $2.4 \mathrm{~mL}$ ( $2.6 \%$ of mean organ volume); for rectal volume, $2.5 \mathrm{~mL}$ (4.6\% of mean organ volume).

\section{Organ Motion}

There was a tendency towards posterior movement of the anterior rectal wall and anterior tendency in the position of the posterior bladder border during the $\mathrm{RT}$ course relative to the $\mathrm{CT}_{\text {ref. }}$ Organ border motion values at SUP, MID, and INF levels are displayed in Table 2. The calculated posterior margin for PF PTV creation ranged from 8.6 to $10.2 \mathrm{~mm}$, while the calculated anterior margin for PF PTV ranged from 5.9 to $7.1 \mathrm{~mm}$ (Table 2). The mean IOD observed on $\mathrm{CT}_{\text {ref }}$ images was $8.0 \pm 5.7 \mathrm{~mm}, 6.8 \pm$ $5.1 \mathrm{~mm}$, and $5.6 \pm 3.5 \mathrm{~mm}$ for the SUP,MID and INF levels, respectively. The average CBCT IOD, based on mean IOD for all patients, was 11.4 $\pm 6.7 \mathrm{~mm}, 9.4 \pm 3.1 \mathrm{~mm}$, and $10.4 \pm 4.2 \mathrm{~mm}$ for the SUP, MID and INF levels, respectively.

\section{Organ Volume}

The bladder and rectum CBCT volumes measured during the course of RT were smaller than those obtained on the planning CT. The average $\mathrm{CT}_{\text {ref }}$ rectum volume was $67.6 \pm 50.5 \mathrm{~mL}$, while the average $\mathrm{CBCT}$ volume was $59.5 \pm 11.3 \mathrm{~mL}$ (8.1 mL difference). For the bladder, the average $\mathrm{CT}_{\text {ref }}$ volume was $152.3 \pm 103.3 \mathrm{~mL}$, while the average CBCT volume was 93.1 $\pm 26.8 \mathrm{~mL}$ (59.2 mL difference). When patients with greater than $50 \%$ difference between $\mathrm{CT}_{\text {ref }}$ and average CBCT organ volume were removed from analysis ( 2 patients for bladder and 2 patients for rectum), the mean difference between average $\mathrm{CT}_{\text {ref }}$ and CBCT volumes decreased to $2.9 \mathrm{~mL}$ for rectum and to $40.7 \mathrm{~mL}$ for bladder.

\section{Volume and Motion Relationships}

Pearson correlation coefficients were calculated to analyze interrelationships among mean organ motion at SUP, MID, and INF levels, as well as the average of all levels, mean organ volume, and mean IOD. Correlation coefficient values are displayed in Table 3, revealing that the largest correlation exists between the anterior rectum border position and the distance between the rectum and bladder, with a correlation coefficient of 0.71 between the average interorgan distance and the average rectal wall position. Figure 4 displays the relationship between rectal motion and rectal volume.
Table 3. Pearson correlation coefficients among mean organ motion and mean organ volume.

\begin{tabular}{lcccc}
\hline & $\begin{array}{c}\text { Bladder } \\
\text { Volume }\end{array}$ & $\begin{array}{l}\text { Rectum } \\
\text { Volume }\end{array}$ & IOD & $\begin{array}{c}\text { Rectum } \\
\text { Motion }\end{array}$ \\
\hline Rectum Motion & & & & \\
SUP & -0.15 & 0.37 & -0.68 & $\mathrm{X}$ \\
MID & -0.01 & 0.25 & -0.56 & $\mathrm{X}$ \\
INF & -0.05 & 0.29 & -0.69 & $\mathrm{X}$ \\
AVG & -0.07 & 0.33 & -0.71 & $\mathrm{X}$ \\
\hline Bladder Motion & & & & \\
SUP & -0.14 & 0.18 & 0.29 & 0.42 \\
MID & -0.14 & 0.17 & 0.18 & 0.43 \\
INF & -0.06 & 0.11 & 0.44 & 0.23 \\
AVG & -0.12 & 0.18 & 0.10 & 0.45 \\
\hline IOD & & & & \\
SUP & 0.04 & -0.26 & $\mathrm{X}$ & $\mathrm{X}$ \\
MID & -0.07 & -0.21 & $\mathrm{X}$ & $\mathrm{X}$ \\
INF & 0.01 & -0.26 & $\mathrm{X}$ & $\mathrm{X}$ \\
AVG & 0.01 & -0.28 & $\mathrm{X}$ & $\mathrm{X}$ \\
\hline
\end{tabular}

\section{Discussion}

The normal tissue anatomy (bladder and rectum) adjacent to the PF CTV was readily definable throughout the course of post-RP RT using CBCT. Relative to the planning CT, a mean posterior shift of the anterior rectal wall was observed on the CBCT images. The mean rectal volume as contoured on CBCT images during RT was less than the mean $\mathrm{CT}_{\text {ref }}$ volume. The rectum border shift and rectal volume change noted in this study may be related to a trend towards reduced rectal volume over time during prostate $\mathrm{RT}^{18-19}$. Our adjusted analysis of rectum volumes, which showed smaller mean variations in rectum volume after the removal of two large, outlying values, suggests that strict adherence to the bowel preparatory regimen may produce a planning $\mathrm{CT}$ that is more representative of the rectum during RT. The recommendation that patients in the current study present to clinic for RT with a full bladder and an evacuated rectum may have contributed to the small level of rectum volume variation observed.

In their study of nine patients receiving weekly CT scans during postRP RT, Fiorino et al report a mean anterior shift of the anterior rectal wall throughout the cranial half of the rectum, but no shift within the caudal half of the rectum ${ }^{15}$. In our study, measurements of rectum and

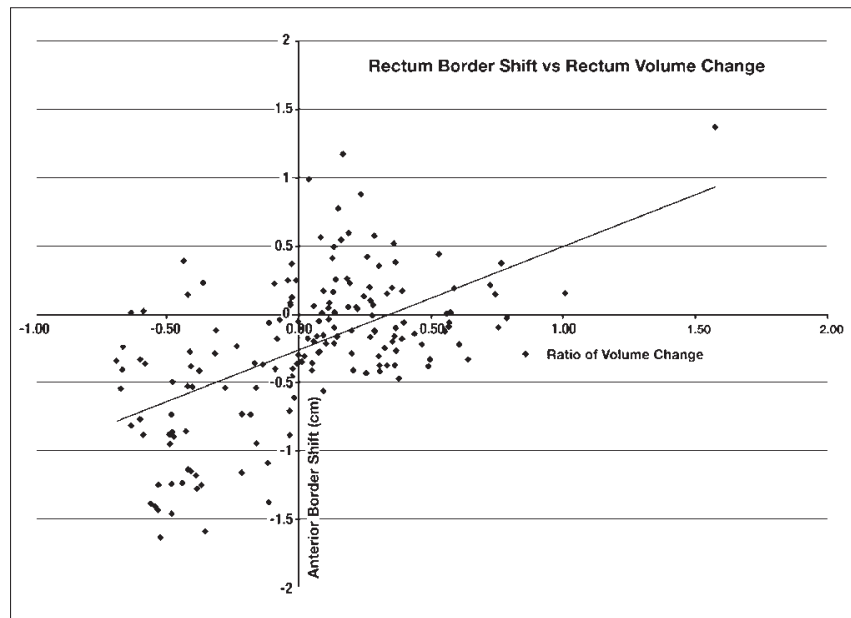

Figure 4. Scatter plot of rectum motion and change in rectum volume. 
bladder shifts were performed only at levels that included the PF CTV. The mean posterior shift of the anterior rectum wall relative to $\mathrm{CT}_{\text {ref }}$ in the current study $(1.6-2.7 \mathrm{~mm})$ was small. The standard deviation of the rectal wall position on $\mathrm{CBCT}$ relative to the $\mathrm{CT}_{\text {ref }}(5.8-6.3 \mathrm{~mm})$ demonstrates important interfraction variation in rectal wall position, noted throughout the region of rectum relevant to the PF CTV, despite the small average shift observed. Variations in rectal volume appear to impact the position of the anterior rectum wall (Figure 4). In addition, the interorgan distance, which may serve as a rough approximation of the prostatic fossa, correlates more strongly with anterior rectal motion than with other factors (Table 3), supporting the influence of rectal border motion on PF CTV delineation.

We recommend the use of a nonuniform margin for PTV definition, consisting of a 5.9 to $7.1 \mathrm{~mm}$ bladder border margin and an 8.6 to 10.2 $\mathrm{mm}$ rectal border margin. A published report of significant correlation between the anterior rectal wall and the prostatic fossa CTV supports, in part, the rationale of the current study's approach, though the reported relationship between rectal and CTV motion occurred only with the cranial portion of the rectum ${ }^{15}$. Although the influence of OAR motion on PF PTV margin definition seems sensible, the extrapolation of target information from organ motion should be approached with caution. The use of 3D conformal RT after RP has been shown to reduce toxicity relative to conventional delivery techniques ${ }^{20}$. In addition, rectal dosevolume histograms (DVHs) for patients undergoing post-RP RT have been shown to correlate significantly with risk for late complications ${ }^{21}$. Retrospective analyses of patients undergoing salvage post-RP RT suggest a benefit from RT doses $64.8 \mathrm{~Gy}$ or higher ${ }^{2-3}$. As higher RT doses are delivered to the prostatic fossa, the ability to minimize toxicity of adjacent tissues rests upon an understanding of motion of both CTV and OARs during treatment. Intensity-modulated radiation therapy (IMRT) may allow safe dose-escalation for post-RP RT ${ }^{22}$, but its application requires detailed target definition guidelines ${ }^{1}$. CBCT may allow tighter RT margins when used to conduct IGRT with daily corrections ${ }^{16}$, potentially allowing for higher total doses without parallel increases in OAR dose and treatment-related toxicity.

The current study provides approximate anterior and posterior margins for PF PTV definition based on calculations using pelvic organ motion information. Lateral margins were not calculated, as lateral movement is less significant than anteroposterior motion ${ }^{9}$ and is unlikely to influence dose delivered to the adjacent organs at risk (bladder and rectum). Due to uncertainty in direct definition of the PF CTV, an indirect approach was utilized based on interfraction rectal and bladder motion. This approach acknowledges the uncertainty of CTV definition ${ }^{12,23}$ while incorporating the additional anatomic information provided by on-line CBCT imaging during the RT course. The bladder and the rectum were easily identified on most CBCT images in the current study. A small number of CBCT images collected in the current study (7\%) were unusable for organ definition due to poor image quality, which may be attributed to technical errors in image acquisition. The use of bladder and rectum movements as determinants for PTV margin guidelines may provide a reliable approach, as rectal contouring has been shown to be reproducible using helical CT scans ${ }^{14}$. These data and similar future studies should be pursued to better define target-definition guidelines for post-RP conformal RT. Avenues for future applications of CBCT images in post-RP RT may include daily online localization with manual soft-tissue registration and subsequent corrective shifts in patient position, as well as off-line adaptive RT based upon a set of CBCT scans obtained during the first week of RT in a fashion similar to that described previously by Yan et $a^{24}$. The current work may be used in future attempts to develop off-line adaptive strategies for RT that rely upon conformal avoidance of the rectum and bladder to target the PF CTV for post-prostatectomy patients.

In conclusion, normal tissue anatomy (bladder and rectum) used to define the anterior and the posterior border of the prostatic fossa was readily definable by CBCT imaging throughout the course of post-RP RT. In the absence of direct, target-based treatment guidelines available, CBCT definition of bladder and rectum volumes may be used to pursue anterior and posterior PTV margin recommendations.

\section{References}

1. Hayes SB, Pollack A. Parameters for treatment decisions for salvage radiation therapy. J Clin Oncol 2005;23:8204-8211.

2. Macdonald OK, Schild SE, Vora SA, et al. Radiotherapy for men with isolated increase in serum prostate specific antigen after radical prostatectomy. J Urol 2003;170:1833-1837.

3. Valicenti RK, Gomella LG, Ismail M, et al. Effect of higher radiation dose on biochemical control after radical prostatectomy for pT3N0 prostate cancer. Int J Radiat Oncol Biol Phys 1998;42:501-506.

4. Stephenson AJ, Shariat SF, Zelefsky MJ, et al. Salvage radiotherapy for recurrent prostate cancer after radical prostatectomy. JAMA 2004;291:1325-1332.

5. Song DY, Thompson TL, Ramakrishnan V, et al. Salvage radiotherapy for rising or persistent PSA after radical prostatectomy. Urology 2002;60:281-287.

6. Morris MM, Dallow KC, Zeitman AL, et al. Adjuvant and salvage irradiation following radical prostatectomy for prostate cancer. Int J Radiat Oncol Biol Phys 1997;38:731-736.

7. Chawla AK, Thakral HK, Zietman AL, et al. Salvage radiotherapy after radical prostatectomy for prostate adenocarcinoma: Analysis of efficacy and prognostic factors. Urology 2002;59:726-731.

8. Valicenti RK, Gomella LG, Ismail M, et al. The efficacy of early adjuvant radiation therapy for pT3N0 prostate cancer: A matched pair analysis. Int J Radiat Oncol Biol Phys 1999;45:53-58.

9. Bolla M, Van Poppel H, Collette L, et al. Postoperative radiotherapy after radical prostatectomy: a randomized controlled trial (EORTC trial 22911). Lancet 2005;366:572-578.

10. Thompson IM Jr, Tangen CM, Paradelo J, et al. Adjuvant radiotherapy for pathologically advanced prostate cancer: a randomized clinical trial. JAMA 2006;296:2329-2335.

11. ASTRO Consensus Panel. Consensus statements on radiation therapy of prostate cancer: Guidelines for prostate re-biopsy after radiation and for radiation therapy with rising prostatespecific antigen levels after radical prostatectomy. J Clin Oncol 1999;17:1155-1163.

12. Symon Z, Tsvang L, Pfeffer R, et al. Prostatic fossa boost volume definition: Physician bias and the risk of planned geographical miss. Scientific Paper, RSNA 2004. [abstract]

13. Jani AB, Spelbring D, Hamilton $\mathrm{R}$, et al. Impact of radioimmunoscintigraphy on definition of clinical target volume for radiotherapy after prostatectomy. J Nucl Med 2004;45:238-246.

14. Foppiano F, Fiorino C, Frezza G, et al. The impact of contouring uncertainty on rectal 3D dosevolume data: results of a dummy run in a multicenter trial (AIROPROS01-02). Int J Radiat Oncol Biol Phys 2003;57:573-579.

15. Fiorino C, Foppiano F, Franzone P, et al. Rectal and bladder motion during conformal radiotherapy after radical prostatectomy. Radiother Oncol 2005;74:187-195.

16. Létourneau D, Martinez AA, Lockman D, et al. Assessment of residual error for online cone-beam CT-guided treatment of prostate cancer patients. Int J Radiat Oncol Biol Phys 2005;62:1239-1246.

17. ICRU. International Commission on Radiation Units and Measurements, Prescribing, Recording, and Reporting Electron Beam Therapy, ICRU Report 71 (International Commission on Radiation Units and Measurements, Bethesda); 2004.

18. Zelefsky MJ, Crean D, Magera GS, et al. Quantification and predictors of prostate position variability in 50 patients evaluated with multiple CT scans during conformal radiotherapy. Radiother Oncol 1999;50:225-234.

19. Lebesque JV, Bruce AM, Kroes APG, et al. Variation in volumes, dose-volume histograms, and estimated normal tissue complication probabilities of rectum and bladder during conformal radiotherapy of T3 prostate cancer. Int J Radiat Oncol Biol Phys 1995;33:1109-1119.

20. Cozzarini C, Fiorino C, Mandelli D, et al. 3D conformal radiotherapy significantly reduces toxicity of post-prostatectomy adjuvant or salvage irradiation. Int J Radiat Oncol Biol Phys 2000;1 (suppl. 1):248.

21. Cozzarini C, Fiorino C, Ceresoli GL, et al. Significant correlation between rectal DVH and late bleeding in patients treated after radical prostatectomy with conformal or conventional radiotherapy (66.6-70.2 Gy). Int J Radiat Oncol Biol Phys 2003;55:688-694.

22. Bastasch MD, Teh BS, Mai Wy, et al. Post-nerve-sparing prostatectomy, dose-escalated intensitymodulated radiotherapy: Effect on erectile function. Int J Radiat Oncol Biol Phys 2000;48:369-375.

23. Fiorino $\mathrm{C}$, Reni $\mathrm{M}$, Bolognesi $\mathrm{A}$, et al. Intra- and inter-observer variability in contouring prostate and seminal vesicles: implications for conformal treatment planning. Radiother Oncol 1998;47:285-92.

24. Yan D, Lockman D, Brabbins D, et al. An off-line strategy for constructing a patient-specific planning target volume in adaptive treatment process for prosate cancer. Int J Radiat Oncol Biol Phys 2000;48:289-302. 